CLINICAL STUDY

\title{
Long-term benefits of testosterone replacement therapy on angina threshold and atheroma in men
}

\author{
Atish Mathur, Christopher Malkin, Basil Saeed ${ }^{1}$, R Muthusamy ${ }^{2}$, T Hugh Jones ${ }^{3,4}$ and Kevin Channer \\ Department of Cardiology, Royal Hallamshire Hospital, Sheffield S1O 2JF, UK, ${ }^{1}$ Department of Cardiology, Barnsley Hospital NHS Foundation Trust, \\ Barnsley S75 2EP, UK, ${ }^{2}$ Department of Cardiology Rotherham District General Hospital, Rotherham S6O 2UD, UK, ${ }^{3}$ Centre for Diabetes and \\ Endocrinology, Barnsley Hospital NHS Foundation Trust, Barnsley S75 2EP, UK and ${ }^{4}$ Academic Unit of Diabetes, Endocrinology and Metabolism, \\ University of Sheffield Medical School, Sheffield S1O 2RX, UK \\ (Correspondence should be addressed to K Channer; Email: kevin.channer@sth.nhs.uk)
}

\begin{abstract}
Introduction: In short-term studies, testosterone replacement therapy has been shown to protect male subjects from exercise-induced ischaemia and modify cardiovascular risk factors such as insulin resistance, fat mass and lipid profiles.

Methods: This randomised parallel group controlled trial was designed to assess the treatment effect of testosterone therapy (Nebido) compared with placebo in terms of exercise-induced ischaemia, lipid profiles, carotid intima-media thickness (CIMT) and body composition during 12 months treatment in men with low testosterone levels and angina.

Results: A total of 15 men were recruited but $13(n=13)$ reached adequate duration of follow-up; seven were treated with testosterone and six with placebo. Testosterone increased time to ischaemia $(129 \pm 48$ s versus $12 \pm 18, P=0.02)$ and haemoglobin $(0.4 \pm 0.6 \mathrm{~g} / \mathrm{dl}$ versus $-0.03 \pm 0.5, P=0.04)$, and reduced body mass index $\left(-0.3 \mathrm{~kg} / \mathrm{m}^{2}\right.$ versus $\left.1.3 \pm 1, P=0.04\right)$ and triglycerides $(-0.36$ $\pm 0.4 \mathrm{mmol} / \mathrm{l}$ versus $0.3 \pm 1.2, P=0.05)$. The CIMT decreased in the testosterone group more than placebo, but full between group analyses suggested this was only a statistical trend $(-0.5 \pm 0.1$ vs $-0.09 \pm 0.06, P=0.16)$. There were no significant effects on serum prostate specific antigen, total or high-density lipoprotein cholesterol; or on mood and symptom scores as assessed by Seattle Angina Score and EuroQol.

Conclusion: The protective effect of testosterone on myocardial ischaemia is maintained throughout treatment without decrement. Previously noted potentially beneficial effects of testosterone on body composition were confirmed and there were no adverse effects.
\end{abstract}

European Journal of Endocrinology $161443-449$

\section{Introduction}

Testosterone is the dominant male sex hormone but in addition it has widespread effects on metabolism and the cardiovascular system. The male-to-female ratio of mortality from vascular disease is $\sim 3: 1$ throughout the world and this ratio is independent of the background prevalence of vascular disease and of other cardiovascular risk factors (1). Recently, three longitudinal epidemiological studies have found low testosterone levels to be associated with an increased risk of all-cause and cardiovascular mortality (2-4). Similarly, studies of men with prostate cancer treated with anti-androgens have also been found to have increased cardiovascular risk (5). There is a gradual fall in serum testosterone levels after the age of 40 years. Late-onset hypogonadism is defined as an age-related deterioration in androgen production causing low serum testosterone levels combined with symptoms of testosterone deficiency. There is no evidence that elevated or high-normal levels of serum testosterone are associated with the onset of vascular disease (6); indeed, biochemical testosterone deficiency is common in male patients with vascular disease. Testosterone replacement in these subjects can lead potentially to beneficial effects. Physiological testosterone replacement has been reported in a number of trials to improve lipid profiles, increase insulin sensitivity, and reduce visceral fat, clotting and inflammatory profiles (reviewed in (7-9)). Importantly, no adverse effects of testosterone replacement therapy on coagulation have been demonstrated in men with chronic stable angina (10). Furthermore, animal studies have shown that testosterone replacement inhibits the development and progression of atheroma (11). Finally, testosterone has direct effects on vascular tone causing vasodilatation, an increase in coronary blood flow $(12,13)$ and an increase in the ischaemic threshold in patients with symptoms of stable angina $(14,15)$. There are, however, 
several questions on the effects of testosterone therapy in men with coronary ischaemia, which remain to be answered.

First, does the effect of testosterone persist in the longterm? Many of the published studies are acute single dose trials and none of the chronic studies have assessed patients formally beyond a few months. Previous clinical studies from our group have been limited to 3 months. There is a concern that in the long term, the vasodilator effects of testosterone replacement on vascular reactivity (16) and the resulting beneficial acute haemodynamic effect would attenuate leading to a drop-off in the clinical effect - as was seen in our 12-month clinical trial of testosterone in heart failure (17). Secondly, does testosterone therapy affect the levels of measurable atheroma? In vivo atheroma measured as carotid intima-media thickness (CIMT) (18) - is a marker of vascular risk and can be used as a surrogate marker of treatment efficacy. Observational studies have consistently shown an inverse relationship between the CIMT and serum testosterone. In follow-up studies, those patients with a low testosterone blood level had bigger changes in CIMT over time, representing increased atheroma progression $(19,20)$. Prospective animal studies are consistent with this and have shown that physiological androgen replacement inhibits atheroma progression $(11,21-23)$. There are currently no in vivo human data on the effects of androgen therapy on atheroma.

In this study, we aim to address these two issues by examining the clinical effects of testosterone replacement therapy in men with angina over a 12-month-period and assessing the progression of carotid atheroma.

\section{Methods}

\section{Subjects}

We recruited ambulant males over 20 years of age with stable, chronic angina pectoris for $>1$ month with proven ST segment depression of $>1 \mathrm{~mm}$ within $12 \mathrm{~min}$ of the Bruce protocol and at least two measurements of early morning serum testosterone $<12 \mathrm{nmol} / \mathrm{l}$.

Patients were excluded if they had used androgen therapy or anabolic steroids within 6 months of entry into the study (i.e. screening visit/visit 1) and had any contraindication to treatment with Nebido, prostate specific antigen (PSA) $\geq 4 \mathrm{ng} / \mathrm{ml}$ or severe symptomatic benign prostatic hyperplasia. Patients actively or potentially trying to start a family or requiring fertility treatment or with any suspicion of, current, or past history of breast or prostatic carcinoma; myocardial ischaemia (MI), coronary artery bypass surgery or percutaneous coronary intervention (PCI) in the last 3 months or significant hepatic, respiratory, haematological or renal disease were also excluded. Further exclusions included haematocrit $>50 \%$ at entry to the study (i.e. screening visit/visit 1), history of drug or alcohol abuse, other trial drugs within 12 weeks, hypercalcaemia, nephrotic-range proteinuria, symptomatic obstructive sleep apnoea syndrome and any electrocardiograph (ECG) abnormalities that preclude ST segment analysis (e.g. left bundle branch block (LBBB), atrial fibrillation (AF)).

Patients were recruited from the ongoing care of cardiologists within the North Trent network. The clinical trial had full Ethics Committee approval and was registered (NCTO0131183). Full informed written consent was obtained.

\section{Study design and treatment}

This was a double-blind, randomised, parallel group placebo-controlled trial.

Patients were screened and randomised between August 2005 and November 2006. At baseline, subjects completed a medical questionnaire, detailing medical history and concomitant medications. Resting pulse, blood pressure, height and weight were recorded, and body mass index (BMI) was calculated (weight $(\mathrm{kg}) /$ height $\left.^{2}\left(\mathrm{~m}^{2}\right)\right)$. Blood was drawn for serum and haematological assessments. Full blood count, fasting serum glucose and insulin and PSA were performed as standard hospital assays. Total testosterone, SHBG, LH and FSH and high sensitivity CRP (hsCRP) were measured by ELISA (DRG Instruments GmbH, Marburg, Germany) and fasting lipids (Olympic Diagnostics, Hamburg, Germany). Calculated measurements of free and bioavailable testosterone were made using published formulae $(24,25)$.

Following trial entry, a 2-week single-blind 'run-in' period during which no trial drug therapy was given, was used to allow accurate recording of angina frequency and ensure that baseline exercise parameters were reproducible to within $10 \%$ (on the basis of two exercise tests at least 1 week apart). After this, a 12-month treatment period with testosterone or placebo was commenced with assessment of patient response at 3, 6 and 12 months (Table 1). The testosterone/placebo treatment was given in addition to concomitant angina treatment.

Drug treatment for angina was not changed during the study and all exercise tests were performed on antianginal therapy. No patient had a coronary intervention during the trial period (surgery or angioplasty).

The primary endpoint was change in time with ST segment depression of $>1 \mathrm{~mm}$ during Bruce protocol exercise testing. Patients underwent standard treadmill exercise ECG testing by the Bruce protocol. The exercise ECG was analysed by continuous computer monitoring of the ST segments in leads II, $V_{2}$ and $V_{6}$. The time taken to reach $1 \mathrm{~mm}$ or more of horizontal or downsloping ST depression was recorded by a single observer.

Assessments of carotid atheroma were made by a single trained operator (A M) using a dedicated ultrasound laptop with standard software (Sonocalc IMT). 
Table 1 Trial programme.

\begin{tabular}{|c|c|c|c|c|c|c|c|c|c|}
\hline \multirow{2}{*}{$\begin{array}{l}\text { Event } \\
\text { Visit no. } \\
\text { Time point }\end{array}$} & \multirow{2}{*}{$\begin{array}{c}\text { Screening } \\
1 \\
\text { Week } 0\end{array}$} & \multirow{2}{*}{$\begin{array}{c}\text { Baseline } \\
2 \\
\text { Week } 2\end{array}$} & \multicolumn{6}{|c|}{ Treatment } & \multirow{2}{*}{$\begin{array}{l}\text { End of study } \\
9 \\
\text { After month } 12\end{array}$} \\
\hline & & & $\begin{array}{c}3 \\
\text { Week } 8\end{array}$ & $\begin{array}{c}4 \\
\text { Week } 14\end{array}$ & $\begin{array}{c}5 \\
\text { Week } 20\end{array}$ & $\begin{array}{c}6 \\
\text { Week } 28\end{array}$ & $\begin{array}{c}7 \\
\text { Week } 32\end{array}$ & $\begin{array}{c}8 \\
\text { Week } 44\end{array}$ & \\
\hline $\begin{array}{l}\text { Patient information/ } \\
\text { informed consent }\end{array}$ & $x$ & & & & & & & & \\
\hline $\begin{array}{l}\text { Demographics and } \\
\text { medical history }\end{array}$ & $X$ & & & & & & & & \\
\hline Baseline findings & $\mathrm{X}$ & $X$ & & & & & & & \\
\hline Pulse, blood pressure & $\mathrm{x}$ & $x$ & & $\mathrm{X}$ & & $x$ & & & $\mathrm{X}$ \\
\hline Exercise test & $\mathrm{X}$ & $x$ & & $\mathrm{X}$ & & $x$ & & & $\mathrm{X}$ \\
\hline Fasting blood tests & $x$ & & & $x$ & & & & & $x$ \\
\hline Serum total testosterone & $\mathrm{x}$ & $\mathrm{x}$ & & $x$ & & $\mathrm{X}$ & & & $x$ \\
\hline Questionnaires & & $\mathrm{x}$ & & & & & & & $x$ \\
\hline CIMT assessed & & $x$ & & & & $\mathrm{X}$ & & & $\mathrm{X}$ \\
\hline Randomisation & & $\mathrm{X}$ & & & & & & & \\
\hline Placebo injection & $\mathrm{x}$ & & & & & & & & \\
\hline TU injection/placebo & & $x$ & $\mathrm{X}$ & & $\mathrm{X}$ & & $\mathrm{X}$ & $\mathrm{X}$ & \\
\hline PSA & $\mathrm{X}$ & & & $\mathrm{X}$ & & $\mathrm{X}$ & & $\mathrm{X}$ & $\mathrm{X}$ \\
\hline
\end{tabular}

Blood tests (high sensitivity CRP, insulin, glucose, lipids). Questionnaires (Seattle Angina Score questionnaire, Beck Depression Inventory, EuroQol). CIMT, carotid intima-media thickness; TU, testosterone undecanoate (Nebido injection); PSA, prostate specific antigen.

Measurements were taken from the left carotid with the patient recumbent. The CIMT was traced in the length of the artery from the common carotid (CCA) into the bulb as far as the internal carotid (ICA). Two automated measurements were automatically generated by the software. The first was the average of mean thickness at each of the three sites (CCA, bulb and ICA) and the second one was the average of the maximum CIMT obtained at each of the three sites (at CCA, bulb and ICA).

Symptoms, quality of life scores and mood were quantified by use of the Seattle Angina Score questionnaire, EuroQol and Beck Depression Inventory, which were completed at trial entry and exit.

Table 2 Baseline data.

\begin{tabular}{|c|c|c|c|c|}
\hline & $\begin{array}{l}\text { Base group } \\
\quad(n=13)\end{array}$ & $\begin{array}{c}\text { Placebo } \\
(n=6)\end{array}$ & $\begin{array}{l}\text { Testosterone } \\
\quad(n=7)\end{array}$ & $\begin{array}{c}\text { Baseline comparison } \\
P \text { value }\end{array}$ \\
\hline Age (years) & $64.8 \pm 7.0$ & $67.8 \pm 7.9$ & $62.1 \pm 5.2$ & 0.17 \\
\hline Total testosterone $(\mathrm{nmol} / \mathrm{l})$ & $9.9 \pm 2.2$ & $10.1 \pm 2.8$ & $9.8 \pm 1.9$ & 0.8 \\
\hline Sex hormone binding globulin (nmol/l) & $26.6 \pm 7.4$ & $25 \pm 6.1$ & $28 \pm 8.3$ & 0.5 \\
\hline Free testosterone $(\mathrm{nmol} / /)^{\mathrm{a}}$ & $0.22 \pm 0.05$ & $0.23 \pm 0.06$ & $0.21 \pm 0.04$ & 0.5 \\
\hline Bio-available testosterone ${ }^{b}$ & $3.3+0.7$ & $3.3+0.8$ & $3.2+0.5$ & 0.7 \\
\hline $\mathrm{FSH}(\mathrm{nmol} / \mathrm{l})$ & $7.0 \pm 4.6$ & $10.0 \pm 5.3$ & $4.3 \pm 1.3$ & 0.05 \\
\hline $\mathrm{LH}(\mathrm{nmol} / \mathrm{l})$ & $4.0+2.6$ & $5.4+1.3$ & $2.7+1.0$ & 0.09 \\
\hline Total cholesterol $(\mathrm{mmol} / \mathrm{l})$ & $4.1 \pm 0.78$ & $4.1 \pm 0.9$ & $4.1 \pm 0.66$ & 0.9 \\
\hline Prostate specific antigen $(\mu \mathrm{g} / \mathrm{l})$ & $1.3 \pm 0.94$ & $0.9 \pm 0.7$ & $1.6 \pm 1.0$ & 0.19 \\
\hline High-sensitivity CRP $(\mu \mathrm{g} / \mathrm{ml})$ & $2.8 \pm 2.8$ & $3.1 \pm 3.9$ & $2.5 \pm 1.9$ & 0.7 \\
\hline Total exercise time (s) & $368.6 \pm 104.1$ & $333.2 \pm 143.5$ & $399.1 \pm 46.2$ & 0.3 \\
\hline Time to ST segment depression (s) & $288.1+92.8$ & $251.2+110.3$ & $319.7+67.5$ & 0.2 \\
\hline Peak METS & $7.5 \pm 1.6$ & $7.1 \pm 2.1$ & $7.9 \pm 1.0$ & 0.5 \\
\hline Haemoglobin (g/dl) & $14.7 \pm 1.1$ & $14.1+1.2$ & $15.2+0.8$ & 0.07 \\
\hline Waist-to-hip ratio & $0.97 \pm .06$ & $0.96 \pm 0.07$ & $0.98 \pm 0.06$ & 0.6 \\
\hline Mass $(\mathrm{kg})$ & $86.9 \pm 17.0$ & $82.5 \pm 18.9$ & $90.6 \pm 15.7$ & 0.42 \\
\hline BMI (mass $/ \mathrm{kg}^{2}$ ) & $29.1+5.3$ & $27.6+5.9$ & $30.4+4.7$ & 0.37 \\
\hline CIMT average $(\mathrm{mm})$ & $1.02 \pm 0.3$ & $1.02 \pm 0.29$ & $1.02 \pm 0.27$ & 0.9 \\
\hline CIMT $\max (\mathrm{mm})$ & $1.3+0.35$ & $1.3+0.4$ & $1.3+0.3$ & 0.8 \\
\hline Diabetes & $\overline{3}$ & $\overline{2}$ & 1 & 0.6 \\
\hline Myocardial infarction & 4 & 3 & 1 & 0.3 \\
\hline$\beta$-Blockers & 9 & 4 & 5 & 0.9 \\
\hline Nitrates & 7 & 2 & 5 & 0.3 \\
\hline Calcium-antagonist & 6 & 2 & 4 & 0.6 \\
\hline Other anti-anginal & 6 & 4 & 2 & 0.3 \\
\hline $\mathrm{CABG} / \mathrm{PCI}$ & $5 / 4$ & $4 / 0$ & $1 / 4$ & $0.1 / 0.1$ \\
\hline
\end{tabular}

CABG, coronary artery bypass surgery; $\mathrm{PCl}$, percutaneous coronary intervention; $\mathrm{CIMT}$, carotid intima-media thickness.

${ }^{\mathrm{a}} \mathrm{Free}$ testosterone as calculated by the method of Vermeulen (23).

${ }^{\mathrm{b}}$ Bio-available testosterone as calculated by Morris \& Malkin (24). 


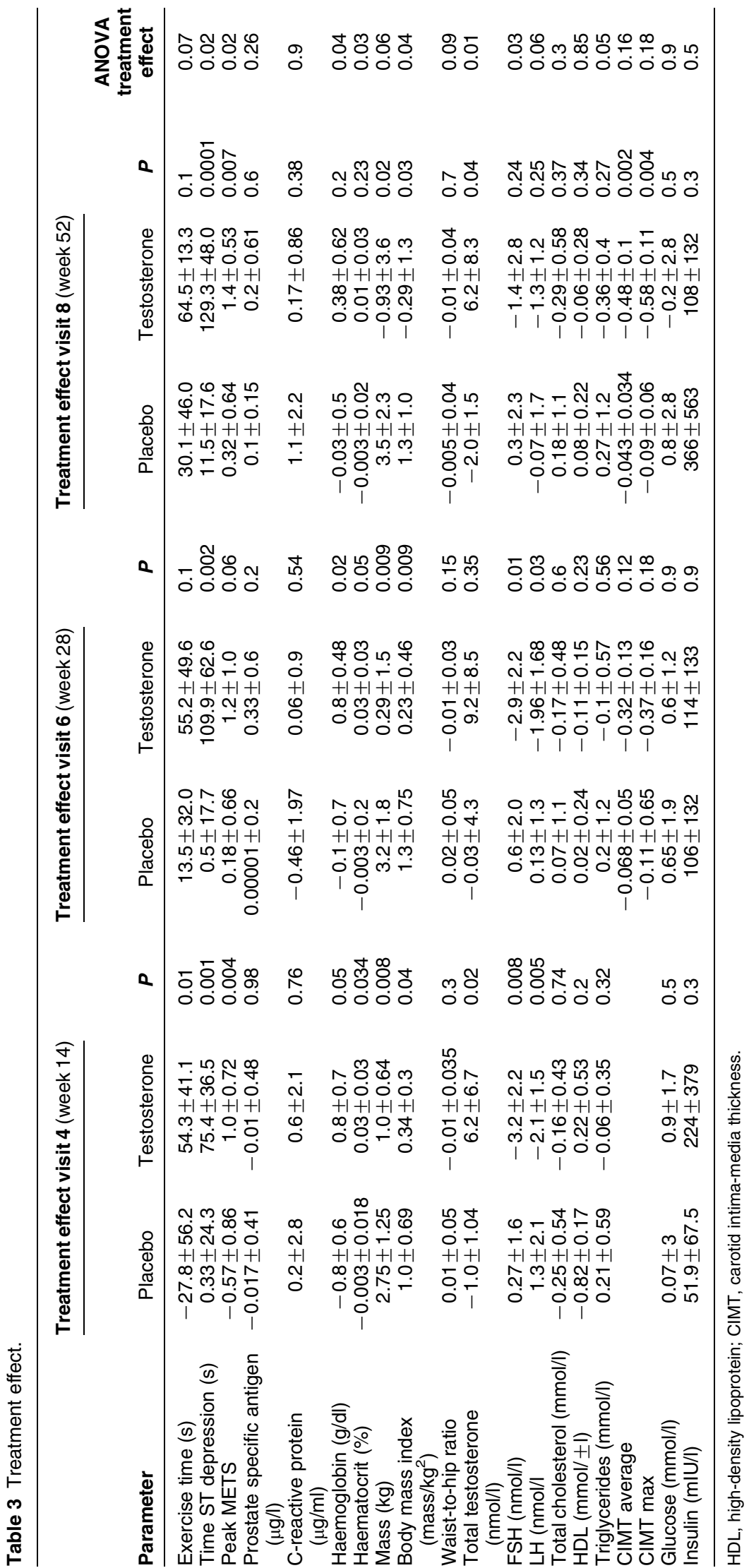


The trial drug used in this study is a novel long-acting depot preparation of testosterone requiring only four injections per year with an additional loading dose after the first 6 weeks, or matching placebo. The i.m. application of the trial drug, Nebido, which contains $1000 \mathrm{mg}$ testosterone undecanoate in $4 \mathrm{ml}$ castor oil, has been shown to maintain the testosterone level within the physiological range for about 12 weeks while largely avoiding non-physiological troughs and peaks (26).

\section{Statistical analysis and power calculation}

The study was powered on the basis of the primary endpoint. We envisaged that most of the patients recruited for this trial would have moderate-to-severe angina. From previous studies in a similar patient group $(14,15)$, we anticipated a treatment effect of around $75 \pm 50 \mathrm{~s}$ improvement in time to $1 \mathrm{~mm}$ ST segment depression. Therefore, assuming a treatment effect delta of $75 \pm 50 \mathrm{~s}$, for a parallel placebo controlled trial with $5 \%$ significance and $80 \%$ power, seven patients would be required in each arm. Randomisation was determined by computer-generated random numbers. All data were tested against a normal distribution with Kolmogorov-Smirnov tests. Data are presented as mean \pm s.D. with analysis based on intention to treat with data carried over from previous visits in the case of patient withdrawal. The treatment effect was defined as the difference between the active treatment delta from baseline and placebo treatment delta from baseline. Data sampled at baseline, 3, 6 and 12 months were analysed by univariate analysis of the variance using a general linear model (SPSS version 14). The dependent variable tested was the change from baseline (e.g. time to ST segment depression); the fixed variables were treatment group and time of sampling. The model incorporated an adjustment for subject effect since the baseline covariate was confounded with the subject variable. The main outcome was the effect of testosterone treatment on time to ischaemic threshold and post-hoc t-tests were calculated for the primary outcome. Parameters sampled twice (questionnaire data) were analysed with the Mann-Whitney U-test. Correlations were tested with Pearson's correlation coefficient for parametric data. Baseline data were compared with unpaired $t$-tests for parametric data and Fisher's exact test for $2 \times 2$ categorical data. In all analyses significance was sought at the $5 \%$ level.

\section{Results}

A total of 15 patients were randomised following the run-in period, seven to placebo and eight to testosterone. Two patients withdrew early in the trial before any outcome assessment could be made, therefore complete data was available on 13 patients. Nebido injections were well tolerated and no patient suffered any major adverse event or unplanned hospital admission. Baseline data are shown in Table 2. The two groups were well matched. The gonadotrophin levels were higher in the placebo group because two patients were found to have manifest hypergonadotrophic hypogonadism with elevated FSH and LH levels. All other patients had a mixed picture with low total testosterone and gonadotrophins in the normal range. Results are presented in Table 3; the treatment effect given as change from the baseline of each time point and analysis of the variance for the full-time period are presented separately. Total testosterone increased and gonadotrophins decreased appropriately with testosterone therapy. Testosterone levels in the treatment group were elevated but maintained within the physiological normal range. The mean trough levels of total testosterone achieved in the treatment arm were $+16.1 \pm 6.7 \mathrm{nmol} / \mathrm{l}$ at week $14,+19.0 \pm 7.8 \mathrm{nmol} / \mathrm{l}$ at week 26 and +16.0 $\pm 7.3 \mathrm{nmol} / \mathrm{l}$ at week 52 . The highest single level of total testosterone was $32 \mathrm{nmol} / \mathrm{l}$ measured in one patient at week 14. Maximal exercise time, time to $1 \mathrm{~mm}$ ST depression and peak metabolic equivalents (METS) achieved all increased testosterone treatment compared with placebo, although a significant effect was only maintained for the whole year in time to ST depression and peak METS. At 12 months, the effective increase in time to ST depression was $117.8 \pm 21 \mathrm{~s}$ giving 95\% confidence limits of (72-164 s; Fig. 1). The increase in time to ST segment depression correlated positively with change in total testosterone at all points of assessment $(r P<0.8, P<0.01$ in each case). Testosterone treatment was associated with small but significant increases in haemoglobin and haematocrit and small decreases in BMI and serum triglycerides; the decreases in total mass and waist-to-hip ratio approached but did not meet acceptable levels of significance. There were no differences in the effect of testosterone treatment on hsCRP, total cholesterol, high-density lipoprotein cholesterol, fasting glucose and insulin or

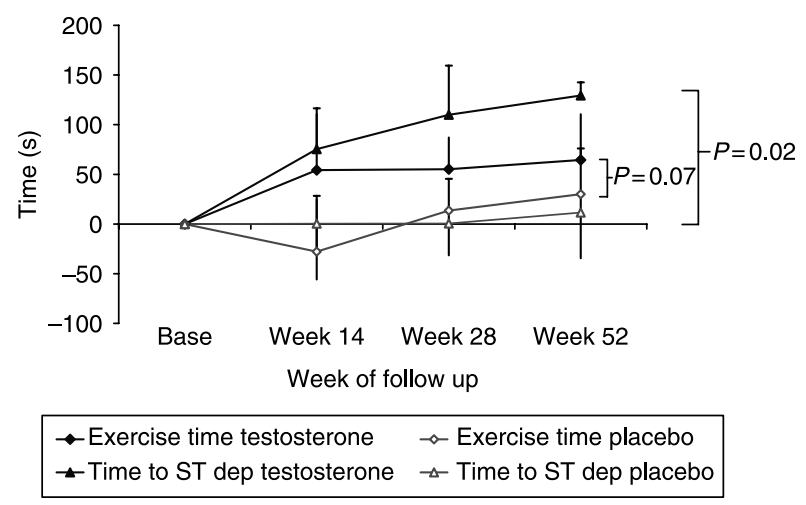

Figure $1 \mathrm{Impact}$ on exercise time and time to $1 \mathrm{~mm} \mathrm{ST} \mathrm{segment}$ depression (analysis by ANOVA). 
serum PSA but serum triglycerides in the treatment group were noted to decrease.

There was no difference between the testosterone treatment group and placebo on quality of life measures. Treatment effect as measured by EuroQol $(-0.9 \pm 1.9, P=0.3)$, Beck Depression Inventory $(0.8 \pm 4.8, P=0.3)$ and Seattle Angina Score (2.1 $\pm 7.6, P=0.1)$ appeared unchanged.

In both measures of carotid atheroma (CIMT), the testosterone group appeared to have greater reductions of CIMT than the placebo treated group, however in the full ANOVA analysis the effect of testosterone treatment on CIMT only approached required levels of significance $(P=0.16$ and $P=0.18)$.

\section{Discussion}

In this study, we have demonstrated that testosterone therapy significantly delays time- to exercise-induced MI. This is consistent with the findings in our previous studies; however, in the present study the clinical effect was maintained and sustained for a longer period of 12 months. This is an important point since previous studies of the effect of testosterone on MI have been of short duration - in some cases comprising only a single i.v. dose of testosterone (27). No trial has followed up patients beyond 3 months (15). There did not appear to be a decrement in the treatment effect of testosterone on ischaemia, a concern that was raised in our previous trials of testosterone in heart failure (17) and vascular reactivity (16). Therefore, we conclude that the antiischaemic effect of testosterone is consistent and maintained without tachyphylaxis for as long as the treatment is continued. Recent in vitro studies have demonstrated that testosterone inhibits L-type calcium channels (28), which is the same site of action as the dihydropyridine calcium antagonist nifedipine, and we postulate that this may be the mechanism of its antiischaemic action $(29,30)$. Its inhibitory effect appears to be of the same order of magnitude as nifedipine.

Our data on the effect of testosterone therapy on carotid atheroma are of significant potential interest. Numerous animal models have demonstrated that physiological testosterone replacement therapy prevents progression of established atheroma and development of nascent atheroma $(11,21)$. This outcome has never been reported in prospective randomised clinical trials of testosterone in humans. Our data show that CIMT measures during replacement therapy with testosterone were reduced compared with placebo, although the effect did not meet accepted standards of clinical significance. It is likely that our data are considerably underpowered for such an outcome since the changes in CIMT in absolute terms were small and the technique is subject to considerable inter- and intra-observer variability. Although in this study our reductions in CIMT are not statistically significant, they support the need for a prospective evaluation of testosterone therapy on the effect of atheroma in humans.

In conclusion, the anti-ischaemic effect of testosterone in men is consistent (in numerous studies) and durable. The next question to answer is whether the testosterone also reduces vascular events and atheroma progression.

\section{Declaration of interest}

There is no conflict of interest that could be perceived as prejudicing the impartiality of the research reported. The authors designed, conducted and analysed the results and wrote the paper. The financial sponsors had no editorial input over this manuscript.

\section{Funding}

This work was supported by Bayer-Schering Pharmaceuticals who provided supplies of Nebido and matching placebo and limited financial support for this study.

\section{Author contribution statement}

Atish Mathur screened and recruited the study patients with the help of Basil Saeed and Rangasamy Muthusamy.

Chris Malkin collected and analysed the trial data and wrote the first draft of the paper.

T Hugh Jones helped design trial protocol, obtained funding and edited the final manuscript.

Kevin Channer designed protocol, obtained ethics, regulatory approval and funding, edited the final manuscript and is the guarantor and corresponding author of the paper.

\section{References}

1 Njolstad I, Arnesen E \& Lund-Larsen PG. Smoking, serum lipids, blood pressure, and sex differences in myocardial infarction. A 12-year follow-up of the Finnmark Study. Circulation 1996 $93450-456$.

2 Shores MM, Matsumoto AM, Sloan KL \& Kivlahan DR. Low serum testosterone and mortality in male veterans. Archives of Internal Medicine 2006166 1660-1665.

3 Khaw KT, Dowsett M, Folkerd E, Bingham S, Wareham N, Luben R, Welch A \& Day N. Endogenous testosterone and mortality due to all causes, cardiovascular disease, and cancer in men: European prospective investigation into cancer in Norfolk (EPIC-Norfolk) prospective population study. Circulation 2007116 2694-2701.

4 Laughlin GA, Barrett-Connor E \& Bergstrom J. Low serum testosterone and mortality in older men. Journal of Clinical Endocrinology and Metabolism 200893 68-75.

5 Ockrim JL \& Abel PD. Long term androgen deprivation therapy in prostate cancer. BMJ 2008337 a1361.

6 Wu FC \& von Eckardstein A. Androgens and coronary artery disease. Endocrine Reviews 200324 183-217.

7 Malkin CJ, Pugh PJ, Jones TH \& Channer KS. Testosterone for secondary prevention in men with ischaemic heart disease? Quarterly Journal of Medicine 200396 521-529.

8 Kapoor D, Malkin CJ, Channer KS \& Jones TH. Androgens, insulin resistance and vascular disease in men. Clinical Endocrinology $200563239-250$.

9 Jones RD, Nettleship JE, Kapoor D, Jones HT \& Channer KS. Testosterone and atherosclerosis in aging men: purported association and clinical implications. American Journal of Cardiovascular Drugs 20055 141-154. 
10 Smith AM, English KM, Malkin CJ, Jones RD, Jones TH \& Channer KS. Testosterone does not adversely affect fibrinogen or tissue plasminogen activator (tPA) and plasminogen activator inhibitor-1 (PAI-1) levels in 46 men with chronic stable angina. European Journal of Endocrinology 2005152 285-291.

11 Alexandersen P, Haarbo J, Byrjalsen I, Lawaetz H \& Christiansen C. Natural androgens inhibit male atherosclerosis: a study in castrated, cholesterol-fed rabbits. Circulation Research $1999 \mathbf{8 4}$ 813-819.

12 Chou TM, Sudhir K, Hutchison SJ, Ko E, Amidon TM, Collins P \& Chatterjee K. Testosterone induces dilation of canine coronary conductance and resistance arteries in vivo. Circulation 199694 2614-2619.

13 Webb CM, McNeill JG, Hayward CS, de Zeigler D \& Collins P. Effects of testosterone on coronary vasomotor regulation in men with coronary heart disease. Circulation 1999100 1690-1696.

14 Malkin CJ, Pugh PJ, Morris PD, Kerry KE, Jones RD, Jones TH \& Channer KS. Testosterone replacement in hypogonadal men with angina improves ischaemic threshold and quality of life. Heart $200490871-876$.

15 English KM, Steeds RP, Jones TH, Diver MJ \& Channer KS. Lowdose transdermal testosterone therapy improves angina threshold in men with chronic stable angina: a randomized, double-blind, placebo-controlled study. Circulation $20001021906-1911$.

16 Malkin CJ, Jones RD, Jones TH \& Channer KS. Effect of testosterone on ex vivo vascular reactivity in man. Clinical Science $2006 \mathbf{1 1 1}$ 265-274.

17 Malkin CJ, Pugh PJ, West JN, van Beek EJ, Jones TH \& Channer KS. Testosterone therapy in men with moderate severity heart failure: a double-blind randomized placebo controlled trial. European Heart Journal 200627 57-64.

18 Kastelein JJ \& de Groot E. Ultrasound imaging techniques for the evaluation of cardiovascular therapies. European Heart Journal 200829 849-858.

19 van den Beld AW, Bots ML, Janssen JA, Pols HA, Lamberts SW \& Grobbee DE. Endogenous hormones and carotid atherosclerosis in elderly men. American Journal of Epidemiology 2003157 25-31.

20 Muller M, van den Beld AW, Bots ML, Grobbee DE, Lamberts SW \& van der Schouw YT. Endogenous sex hormones and progression of carotid atherosclerosis in elderly men. Circulation 2004109 2074-2079.
21 Nettleship JE, Jones TH, Channer KS \& Jones RD. Physiological testosterone replacement therapy attenuates fatty streak formation and improves high-density lipoprotein cholesterol in the Tfm mouse: an effect that is independent of the classic androgen receptor. Circulation $2007 \mathbf{1 1 6} 2427-2434$.

22 Nathan L, Shi W, Dinh H, Mukherjee TK, Wang X, Lusis AJ \& Chaudhuri G. Testosterone inhibits early atherogenesis by conversion to estradiol: critical role of aromatase. PNAS 2001 98 3589-3593.

23 Hanke H, Lenz C, Hess B, Spindler KD \& Weidemann W. Effect of testosterone on plaque development and androgen receptor expression in the arterial vessel wall. Circulation $2001 \mathbf{1 0 3}$ $1382-1385$.

24 Vermeulen A, Verdonck L \& Kaufman JM. A critical evaluation of simple methods for the estimation of free testosterone in serum. Journal of Clinical Endocrinology and Metabolism $1999 \mathbf{8 4}$ 3666-3672.

25 Morris PD, Malkin CJ, Channer KS \& Jones TH. A mathematical comparison of techniques to predict biologically available testosterone in a cohort of 1072 men. European Journal of Endocrinology $2004151241-249$.

26 Nieschlag E, Buchter D, Von Eckardstein S, Abshagen K, Simoni M \& Behre HM. Repeated intramuscular injections of testosterone undecanoate for substitution therapy in hypogonadal men. Clinical Endocrinology 199951 757-763.

27 Rosano GM, Leonardo F, Pagnotta P, Pelliccia F, Panina G, Cerquetani E, della Monica PL, Bonfigli B, Volpe M \& Chierchia SL. Acute anti-ischemic effect of testosterone in men with coronary artery disease. Circulation 199999 1666-1670.

28 Hall J, Jones RD, Jones TH, Channer KS \& Peers C. Selective inhibition of L-type $\mathrm{Ca}^{2+}$ channels in A7r5 cells by physiological levels of testosterone. Endocrinology $20061472675-2680$.

29 Scragg JL, Jones RD, Channer KS, Jones TH \& Peers C. Testosterone is a potent inhibitor of L-type $\mathrm{Ca}(2+)$ channels. Biochemical and Biophysical Research Communications 2004318 503-506.

30 Scragg JL, Dallas ML \& Peers C. Molecular requirements for L-type $\mathrm{Ca}^{2+}$ channel blockade by testosterone. Cell Calcium $20074211-15$.

Received 8 June 2009

Accepted 19 June 2009 